\title{
Prevalence of Dysmenorrhea in Adolescents in France: Results of a Large Cross-Sectional Study
}

\author{
Oum-Keltoum Hadjou ${ }^{1}$, Adeline Jouannin ${ }^{1}$, Vincent Lavoue ${ }^{1}$, Jean Levêque ${ }^{1}$, Maxime \\ Esvan $^{1}$, and Maud Bidet ${ }^{2}$ \\ ${ }^{1}$ Rennes 1 University \\ ${ }^{2}$ Centre Hospitalier Universitaire de Rennes
}

July 21, 2020

\begin{abstract}
Objective: To evaluate the prevalence of dysmenorrhea in adolescents and its impact on daily living. Design: A cross-sectional, questionnaire-based study Setting: Multicenter study in eight randomly selected high schools in France. Population: Randomly selected post-menarche girl pupils 15 -19 years Methods: Each girl was asked to complete a 50-item questionnaire. Main Outcome Measures: Dysmenorrhea severity was assessed with the Numerical Rating Scale (NRS) and Verbal Multidimensional Scoring System Scale (VMSS). Results: Questionnaires from 953 girls were analyzed (mean age: 16.9 years). The prevalence of dysmenorrhea was $92.9 \%$ with $8.9 \%$ describing their pain as severe. Impact on quality of life was significant: $43.3 \%$ of the girls reported school absences because of dysmenorrhea, $74.9 \%$ difficulties in attending classes and $77.2 \%$ difficulties in sports activities. Risk factors of severe dysmenorrhea (VMSS grade 3) in multivariate analysis were heavy menstrual bleeding (OR $2.02,95 \%$ CI $[1.12 ; 3.63] \mathrm{p}=0.0192$ ), early menarche (OR 0.68, 95\%CI $[0.57 ; 0.81] \mathrm{p}<0.0001$ ), chronic pelvic pain (OR 2.60, $95 \%$ CI $[1.10 ; 6.11] \mathrm{p}=0.0274)$, BMI $(\mathrm{BMI}<18$, OR $1.94,95 \%$ CI $[1.03 ; 3.66] \mathrm{p}=0.0335)$. Of the $50.4 \%$ who had consulted a physician, $45.4 \%$ had seen a general practitioner. Among the girls who had not consulted a physician, $55.1 \%$ reported that menstruation was a "woman's burden". Conclusion: Dysmenorrhea is highly prevalent in adolescents in France and has a real impact on daily life activities. As such, it should be treated as a public health problem with educational and information campaigns targeting the girls themselves, their families and healthcare professionals.
\end{abstract}

\section{Keywords: Dysmenorrhea, Adolescent girls, Prevalence, Menstruation}

\section{Tweetable abstract}

Dysmenorrhea is a public health issue with a high prevalence and causing serious social and educational impact in adolescents.

\section{INTRODUCTION}

Dysmenorrhea is the most common gynecological complaint linked to menstruation in young adult women and adolescents. It can either be primary (also known as functional) in the absence of pelvic pathology, or secondary if the pain is attributable to a pelvic pathology such as endometriosis. Primary dysmenorrhea is defined as cyclical pelvic pain that precedes and/or occurs during menstruation in the absence of an underlying organic pathology. It often begins in adolescence, usually within 6 months to 2 years after menarche, when the menstrual cycles become ovulatory $(1,2)$. It is characterized by lower abdominal or lower back cramping pain, which may radiate to the inguinal region or the legs. Symptoms typically begin with the menstrual flow, or the day before, last for 2 to 3 days reaching their peak with the maximum menstrual flow, 
and are more or less similar from one cycle to another. Many adolescents suffering from dysmenorrhea also suffer from other menstruation-associated symptoms like headaches, nausea, vomiting, motility disorders, asthenia, irritability, and myalgia $(1,3)$. The pathophysiological mechanisms of dysmenorrhea are well known $(4,5)$ : overproduction of uterotonic and vasoconstrictor agents and an increased level of circulatory and menstrual rates of PGF2 induce myometrium ischemia, a perception of cramping pain and systemic symptoms $(6,7)$.

Despite being one of the leading causes of recurrent short-term school or work absenteeism among female adolescents (1), data about dysmenorrhea is scarce and contradictory. The reported prevalence of dysmenorrhea in the literature varies considerably from an estimated $21 \%$ in the latest 1984 French study (6) to as high as $94 \%$ in a study conducted in Oman (8). Similarly, the prevalence of severe dysmenorrhea also varies ranging from $12.4 \%$ in 2002 in Switzerland (9) to $42 \%$ in 1998 in the United States (10). Furthermore, despite the availability of effective, easy-to-use and accessible therapeutic methods (4), many girls do not seek medical advice for dysmenorrhea and few use pharmacological treatment $(6,11)$. Overall, given its prevalence and impact on quality of life, dysmenorrhea should be both better documented and managed $(7,11)$.

The main objective of the present study was to determine the prevalence of dysmenorrhea within adolescent girls in France today. The secondary objectives were to define the prevalence of severe dysmenorrhea and identify its risk factors, to assess how girls with dysmenorrhea experience their menses, the consequences on daily living activities or at school, physical, psychological and social repercussions, how they manage their pain and what their expectations are.

\section{MATERIALS AND METHODS}

\section{Design}

The study was conducted as a multicenter quantitative cross-sectional study. The reporting of the study follows the STROBE statement (12).

Recruitment and inclusion criteria

The sample included high school girls aged 15 to 19 years old, who already had their menses, and who attended school in Ille-et-Vilaine, Brittany, France. Girls who had experienced primary or secondary amenorrhea for more than 6 months in the past year were excluded from analysis. The period of inclusion was April and May 2019. A random sampling without replacement was performed to select eight private and public high schools, all levels included. In each high school, we asked the school nurse or the director to randomly select two or three classes from each year $\left(10^{\text {th }}\right.$ to $12^{\text {th }}$ grade) to include about 100 to 150 girls. The girls and their parents received information about the study around 10 days before inclusion; only adolescents who agreed to participate were included. In each high school, the participants were gathered in a classroom or the amphitheater with the main investigator and asked to complete an anonymous questionnaire of 50 questions. No boys were present to ensure that the girls felt free and confident enough to complete the questionnaire in the most frank way. After completion, which took about 20 to 30 minutes, the main investigator immediately retrieved the questionnaires. After the study, a health and drugs-information lesson was given to the adolescents to educate them about dysmenorrhea and how to manage it.

\section{Outcome measures}

The main outcome measure was the prevalence of dysmenorrhea, defined as painful menstruation with cramping sensation in the lower abdomen or lower back, occurring with the menstrual flow or the day before. Severity was assessed according to the intensity of pain, measured by a Numerical Rating Scale, and according to other factors by the Verbal Multidimensional Scoring System (VMSS) (13). More specifically, the VMSS assesses pain intensity, the presence of systemic symptoms, the impact on daily activities and the need for analgesic treatment. Grade 0 corresponds to the absence of dysmenorrhea, and grades 1, 2 and 3 
to mild, moderate and severe dysmenorrhea, respectively. Grade 1, or mild dysmenorrhea was defined as painful menstruation which rarely required pain relief and seldom inhibited daily activities. Grade 2, was defined as moderately painful menstruation which affected daily activities, but with pain killers providing sufficient relief so that absenteeism was unusual. Grade 3, or severe dysmenorrhea, was defined as extremely painful menstruation associated with vegetative symptoms (headache, asthenia, vomiting, diarrhea), reduced daily activities, and no relief by pain killers.

Data collection

The 50-question self-assessment questionnaire collected socio-demographic information, the age of menarche, characteristics of the cycles (including length of the cycle and regularity, duration of the menses and perception of volume), the presence of dysmenorrhea, and the girls' expectations for information about menstruation and dysmenorrhea. Only the girls who suffered from dysmenorrhea were asked to complete the second part of the questionnaire about menstrual pain, its features and repercussions. The girls were also asked about the way they managed their pain, whether they sought medical advice or not, used pharmacological or non-pharmacological treatment, or self-medicated. The questionnaire covered all the items of the VMSS (13).

Target number of participants

Due to the wide variation in the reported prevalence of dysmenorrhea, from $21 \%$ to $94 \%$ in the literature $(8-10,14)$, the calculation of the required sample size was maximized using a prevalence of dysmenorrhea of $50 \%$. With a precision of $5 \%$ and alpha-risk of $0.05,385$ subjects were needed. We decided to double the sample size to obtain sufficient responses for the second part of the questionnaire which was only completed by the girls who had dysmenorrhea $(n=770)$.

Statistical analysis

The prevalences of dysmenorrhea and severe dysmenorrhea were calculated and a descriptive analysis of the population was carried out. Qualitative variables were described as numbers and percentages, and quantitative variables as numbers, means and standard deviation. For group comparisons, the Chi-square or Fisher's exact tests were used for qualitative variables, and Student's t-test or ANOVA for quantitative variables. The population was compared according to i) dysmenorrhea and ii) the severity of dysmenorrhea (grade 1, grade 2, grade 3). Chi-square or Fisher's exact tests were used to compare the distributions of qualitative variables, as well as Student's t-tests or ANOVA for quantitative variables. Risk factors for severe dysmenorrhea were identified by logistic regression and presented by Odds Ratios (OR) and their confidence intervals. Variables with a P-value lower than 0.15 in the univariate analysis were included in a multivariate model. Statistical analyses were conducted among the subgroup of adolescent girls without hormonal contraceptives. A P-value under 0.05 was considered as significant. To account for missing data (i.e., incomplete responses), percentage values were calculated according to the number of answers received for each question. All statistical analyses were performed using SAS V9.4 software (SAS Institute, Cary, NC, USA).

Ethics

We obtained authorization from the relevant authorities to conduct the study within private and public high schools: Diocesan Direction of Catholic Education (February 2, 2019) and the Academy of Rennes (March 7, 2019), respectively. We also obtained approval from the Ethics Committee of Montpellier University Hospital on March 12, 2019.

\section{RESULTS}

\section{Descriptive analysis}

A total of 979 adolescent girls were invited to participate and none refused. Twenty-six girls were excluded from analysis mainly because of age or primary or secondary amenorrhea: two were under 15 years; 10 were 
over 19 years; two had primary amenorrhea; 10 secondary amenorrhea with progestogen-only pill; one had only 1 month of menarche; and for one the cause was unknown (S1).

The population and cycle characteristics are described in Table 1 . Sixty-three percent $(n=600)$ of the girls were enrolled in the public sector. The average age of the whole population was 16.9 years $( \pm 1.0)$ and the average age of menarche was 12.5 years $( \pm 1.4)$. Most $(88.3 \%, n=835)$ had regular cycles, and the menstrual periods were heavy for $58.4 \%(\mathrm{n}=548)$ of the girls. A first-degree family history of dysmenorrhea was reported by $43.2 \%(\mathrm{n}=412)$ of the girls.

Around a third $(36.6 \%, \mathrm{n}=347)$ of the girls claimed to have had sexual relations. Contraception was used by $41.6 \%(\mathrm{n}=396)$ and was an oral contraceptive pill $(\mathrm{OCP})$ for $72.2 \%(\mathrm{n}=286)$. Of the girls taking oral contraception, $67 \%(\mathrm{n}=192)$ were able to say what kind they were taking and $93 \%(\mathrm{n}=178)$ of these were using a combined OCP (COCP). Nearly all $(93 \%, \mathrm{n}=266)$ were taking an OCP for reasons other than contraception and to decrease dysmenorrhea for $62 \%(n=165)$ (Table 1).

In the group of girls with dysmenorrhea, menstruation was associated with asthenia for $92.8 \%(\mathrm{n}=819)$, headache for $77.7 \%(\mathrm{n}=686)$, bloating for $74.9 \%(\mathrm{n}=655)$, and nausea for $39 \%(\mathrm{n}=345)$. Moreover, $43.3 \%$ $(\mathrm{n}=383)$ reported already having missed school, $74.9 \%(\mathrm{n}=660)$ difficulties in attending school and $76.3 \%$ $(n=669)$ poor quality sleep because of their periods (Figure 1).

\section{Outcome measures}

The prevalence of dysmenorrhea was $92.9 \%(\mathrm{n}=885)$ : mild (grade 1) for 18.8\% ( $\mathrm{n}=179)$; moderate (grade 2 ) for $65.2 \%(\mathrm{n}=621)$; and severe (grade 3$)$ for $8.9 \%(\mathrm{n}=85)$ (Table2).

\section{Factors associated with severe dysmenorrhea}

Body mass index (BMI) $(\mathrm{p}=.007)$, active smoking $(\mathrm{p}=.006)$, young age at menarche $(\mathrm{p}<.001)$, long $(\mathrm{p}=.022)$ and heavy $(\mathrm{p}<.001)$ periods were significantly associated with grade 3 dysmenorrhea in univariate analysis (Table 3 ).

Multivariate analysis showed a significant correlation between severe dysmenorrhea and BMI (leanness), young age at menarche, heavy menstruation, the presence of inter-menstrual pain and contraceptive use (Table 3).

\section{Subgroup analysis}

Statistical analyses were conducted among the subgroup of adolescent girls without hormonal contraceptives $(\mathrm{n}=644)$ and showed similar results: the prevalence of dysmenorrhea was $92.4 \%(\mathrm{n}=595)$, with severe dysmenorrhea occurring in 6.8\% ( $\mathrm{n}=44)$ (Appendix 2). More adolescents in this group had heavier menstrual periods $(\mathrm{p}=.042)$ and inter-menstrual pain $(\mathrm{p}<.001)$ than the whole cohort of girls with dysmenorrhea.

\section{Individual management of pain, and adolescent girls' expectations}

High school girls had already taken medication as part of their dysmenorrhea, in $91 \%$ ( $\mathrm{n}=804)$ of cases, with $86.7 \%(\mathrm{n}=697)$ adolescents taking Paracetamol, $68.8 \%(\mathrm{n}=553)$ antispasmodics and $52.4 \%(\mathrm{n}=421)$ non-steroidal anti-inflammatories (NSAIDs). They reported NSAIDs as effective in $67.5 \%$ of cases $(\mathrm{n}=284)$, $52.4 \%(\mathrm{n}=290)$ for antispasmodics and $46.1 \%(\mathrm{n}=321)$ for Paracetamol. It was self-medication for $58.8 \%$ $(\mathrm{n}=471)$ of the sample, with treatment being taken when the pain was severe in $63.3 \%$ of cases $(\mathrm{n}=507)$. If a first dose of medication was ineffective, $40.3 \%(n=234)$ of young girls did not repeat the dose, and $50.2 \%$ $(\mathrm{n}=285)$ did not change drug class. Drug efficacy after 3 months of use was considered partial at $59.6 \%$ $(\mathrm{n}=434)$ and nil at $22.1 \%(\mathrm{n}=161)(\mathrm{S} 3)$.

Their answers to how they managed their pain, the effectiveness of the medication, and the use of nonpharmacological treatment are reported (S3).

Although $77.2 \%(\mathrm{n}=683)$ of the girls had sought advice from their parents and $52.6 \%(\mathrm{n}=465)$ from friends, $49.5 \%(n=438)$ had never consulted a doctor about this issue even if $62.3 \%(n=513)$ believed that a doctor 
could help. Of those who had already sought medical advice, $45.4 \%(\mathrm{n}=401)$ turned to a physician and $12.4 \%$ $(\mathrm{n}=110)$ to a gynecologist. As many as $83.3 \%(\mathrm{n}=788)$ expressed a desire to have access to more information (S3).

\section{DISCUSSION}

\section{Mains findings}

The prevalence of dysmenorrhea in our study of 953 French girls aged 15 to 19 years was high at $92.9 \%$. Their dysmenorrhea was moderate for $65.2 \%$ and severe for $8.9 \%$. Our findings also show that dysmenorrhea has a strong impact on daily life, as $43.3 \%$ of the girls reported school absences, $74.9 \%$ difficulties in attending classes and $77.2 \%$ difficulties in sports activities.

This high prevalence of dysmenorrhea is in accordance with Parker et al. who found a prevalence of $93 \%$ in a sample of 1,055 girls aged 15 to 19 years old in Australia in 2010 (15). However, reported prevalence of dysmenorrhea in the literature ranges from an estimated $56 \%$ in 2012 in Italy (14), $86.6 \%$ in 2012 in Switzerland (9), $94 \%$ in 2011 in Oman (8), and at $21 \%$ out of 4,203 adolescent girls in the latest French prevalence study published in 1984 (6). This wide variation is attributed to different factors, mainly methodological: different definitions of dysmenorrhea, different study populations with non-representative samples, a lack of standard methods for assessing the severity of dysmenorrhea; and sociocultural factors which may have an impact in the perception of this subjective symptom. The present study showed independent risk factors of severe dysmenorrhea - a low BMI, young age at menarche, heavy periods, inter-menstrual pain and the use of contraception - which have also been identified in previous publications $(4,5,16,17)$. Similarly, previous studies have also found that dysmenorrhea has academic, social and professional consequences and is responsible for limitations in daily life activities, sleep disorders, concentration difficulties, reduced intellectual capacity, loss of self-confidence and social withdrawal $(15,18)$.

Our study also highlights ineffective use of drugs by adolescents with dysmenorrhea: waiting for too long before intake (when the pain was severe) to be effective; not taking a second dose when the first failed to relieve the pain; and not changing the drug class if the first one was ineffective. In our population, nearly $60 \%$ of the girls were self-medicating. Overall, $91 \%$ had already taken a pharmacological treatment, mainly acetaminophen and antispasmodics, and half had taken an NSAID. This erratic self-medication behavior reflects a lack of knowledge of therapeutic solutions. Numerous studies have shown that NSAIDs alone have an efficacy of $70-100 \%$ to relieve dysmenorrhea $(9,19,20)$. In our study, although a large majority of the girls asked their parents for advice, almost half of them had never consulted a doctor for their dysmenorrhea, illustrating reticence as has previously been shown $(6,9,10,15,21,22)$. Among those who did consult a doctor, almost $80 \%$ only did so after being advised by someone close to them and not on their own initiative. Despite this, more than $80 \%$ expressed a real desire for information about dysmenorrhea, and more than $60 \%$ would have liked the subject to be brought up spontaneously by their doctor. General practitioners are often the first doctors seen and play a crucial role in the detection and management of dysmenorrhea. Therefore, it is essential for them to be more aware and better trained to screen their adolescent girl patients for cycle disorders (5), and not to misdiagnose secondary dysmenorrhea (23).

Furthermore, among the obstacles to medical consultation, adolescents reported believing that dysmenorrhea was a normal part of the menstrual cycle and that there was no effective solution. Suffering from menstrual pain seems to be accepted as "normal" in our society as reflected in literature reporting studies from around the world $(6,7,9,22)$. However, given the simple and effective therapies available, this currently held belief deserves to be challenged. Beyond the monthly pain experienced by girls individually on a collective scale, it is difficult to accept the consequent negative socio-professional impact in our society in this day and age, when parity constitutes a major challenge worldwide.

Accordingly, public health measures should be implemented to provide information and health education in order to improve the management of dysmenorrhea. Adolescent girls should be better informed through 
the media, large-scale information campaigns, and collective actions in schools carried out by school nurses. It has recently been shown that a brief information campaign targeting adolescent girls providing simple self-medication advice significantly reduces the prevalence and severity of dysmenorrhea, with a benefit on quality of life (24).

\section{Strengths and limitations}

Our study of the prevalence of dysmenorrhea represents a major update of French data on the subject, the last one dating from 1984. The high number of participants (953 girls) with an excellent participation rate (none of the selected girls refused to participate), and the methodology are all parameters that ensure the accuracy of the sample. However, there remain a few limitations to our study. As it was a cross-sectional study, the girls were only asked about their cycles during the past year and our results do not describe the progression of dysmenorrhea over time. Finally, we also had to deal with memory bias that was difficult to overcome, as many girls did not know, or even remember, which pharmacological treatment they had used for their dysmenorrhea.

\section{CONCLUSION}

In our population of 953 adolescent girls in France aged 15 to 19 years, 92\% suffered from dysmenorrhea, $8.9 \%$ of whom experienced severe dysmenorrhea. The factors associated with severe dysmenorrhea identified in multivariate analysis were heavy menstruation, young age at menarche, inter-menstrual pain and a low BMI. The girls often sought symptom-relief through ineffective self-medication and were often of the opinion that menstrual pain was a "womanly burden".

Underdiagnosed, undertreated, trivialized and insufficiently taken into consideration, dysmenorrhea is nevertheless the cause of physical, educational, social and psychological repercussions and can sometimes be an obstacle to the educational and professional progress of the young girls affected. It is therefore essential that this symptomatology be considered a public health issue.

Better information provided to adolescents, as well as to their families and school nurses, could encourage them to consult a physician for access to an effective therapeutic option. Furthermore, general practitioners, the primary care providers, should be trained to actively screen their adolescent girl patients to improve dysmenorrhea management and not to misdiagnose secondary dysmenorrhea.

\section{Disclosure of interests}

None declared. Completed disclosure of interests forms are available to view inline as supporting information.

Contribution to authorship

Conceptualisation: $\mathrm{OKH}, \mathrm{MB}$

Methodology: OKH, MB, ME, AJ

Data collection: $\mathrm{OKH}$

Statistical analysis: ME

Data interpretation: $\mathrm{OKH}, \mathrm{MB}, \mathrm{ME}$

Manuscript draft: OKH, MB, VL, AJ

Manuscript review and editing: OKH, MB, VL, JL, ME, AJ

Details of ethics approval

This cross-sectional study required the authorization from the relevant authorities to conduct the study within private and public high schools: Diocesan Direction of Catholic Education (February 2, 2019) and the 
Academy of Rennes (March 7, 2019), respectively. We also obtained approval from the Ethics Committee of Montpellier University Hospital on March 12, 2019 (ID-RCB: 2019-A00302-55, clinical trial number: NCT04007471)

Funding

None

\section{REFERENCES}

1. ACOG Committee Opinion No. 760: Dysmenorrhea and Endometriosis in the Adolescent. Obstetrics \& Gynecology. déc 2018;132(6):e249-58.

2. Kho KA, Shields JK. Diagnosis and Management of Primary Dysmenorrhea. JAMA. 21 janv 2020;323(3):268.

3. Harel Z. Dysmenorrhea in adolescents. Annals of the New York Academy of Sciences. 2008;1135(1):185-95.

4. Harel Z. Dysmenorrhea in adolescents and young adults: an update on pharmacological treatments and management strategies. Expert Opinion on Pharmacotherapy. 2012;13(15):2157-70.

5. Ryan SA. The treatment of dysmenorrhea. Pediatric Clinics of North America. 2017;64(2):331-42.

6. Sultan C, Gaspari L, Paris F. Adolescent dysmenorrhea. In : Sultan C, ed. Pediatric and adolescent gynecology. Evidence-based clinical practice, 2nd, revised and extended edition. Endoc Dev. Basel : Karger. Endocr Dev. 2012;22:171-80.

7. Iacovides S, Avidon I, Baker FC. What we know about primary dysmenorrhea today: a critical review. Hum Reprod Update. 2015;21(6):762-78.

8. Al-Kindi R, Al-Bulushi A. Prevalence and impact of dysmenorrhoea among Omani high school students. Sultan Qaboos Univ Med J. 2011;11(4):485-91.

9. Narring F, Yaron M, Ambresin A-E. Dysmenorrhea: a problem for the pediatrician? Archives de Pediatrie. 2012;19(2):125-30.

10. Banikarim C, Chacko MR, Kelder SH. Prevalence and impact of dysmenorrhea on Hispanic female adolescents. Arch Pediatr Adolesc Med. 2000;154(12):1226-9.

11. Nur Azurah AG, Sanci L, Moore E, Grover S. The quality of life of adolescents with menstrual problems. Journal of Pediatric and Adolescent Gynecology. 2013;26(2):102-8.

12. von Elm E, Altman DG, Egger M, Pocock SJ, Gotzsche PC, Vandenbroucke JP, et al. The Strengthening the Reporting of Observational Studies in Epidemiology (STROBE) statement: guidelines for reporting observational studies. J Clin Epidemiol. avr 2008;61(4):344-9.

13. Sundell G, Milsom I, Andersch B. Factors influencing the prevalence and severity of dysmenorrhoea in young women. BJOG: An International Journal of Obstetrics \& Gynaecology. 1990;97(7):588-94.

14. Rigon F, De Sanctis V, Bernasconi S, Bianchin L, Bona G, Bozzola M, et al. Menstrual pattern and menstrual disorders among adolescents: an update of the Italian data. Italian Journal of Pediatrics. 2012;38(1):38.

15. Parker MA, Sneddon AE, Arbon P. The menstrual disorder of teenagers (MDOT) study: determining typical menstrual patterns and menstrual disturbance in a large population-based study of Australian teenagers. BJOG: An International Journal of Obstetrics \& Gynaecology. 2010;117(2):185-92.

16. Ju H, Jones M, Mishra G. The prevalence and risk factors of dysmenorrhea. Epidemiologic Reviews. 2014;36(1):104-13. 
17. Grandi G, Ferrari, Xholli, Cannoletta, Palma, Volpe, et al. Prevalence of menstrual pain in young women: what is dysmenorrhea? Journal of Pain Research. 2012;(5):169-74.

18. Zannoni L, Giorgi M, Spagnolo E, Montanari G, Villa G, Seracchioli R. Dysmenorrhea, absenteeism from school, and symptoms suspicious for endometriosis in adolescents. Journal of Pediatric and Adolescent Gynecology. 2014;27(5):258-65.

19. Marjoribanks J, Proctor M, Farquhar C, Derks RS. Nonsteroidal anti-inflammatory drugs for dysmenorrhoea. Cochrane Database of Systematic Reviews 2010. 2010;20 : CD001751.

20. Dawood MY. Primary dysmenorrhea: advances in pathogenesis and management. Obstetrics \& Gynecology. 2006;108(2):428-41.

21. O'Connell K, Davis AR, Westhoff C. Self-treatment patterns among adolescent girls with dysmenorrhea. Journal of Pediatric and Adolescent Gynecology. 2006;19(4):285-9.

22. De Sanctis V, Soliman AT, Daar S, Di Maio S, Elalaily R, Fiscina B, et al. Prevalence, attitude and practice of self-medication among adolescents and the paradigm of dysmenorrhea self-care management in different countries. Acta Biomed. 19 mars 2020;91(1):182-92.

23. Zondervan KT, Becker CM, Missmer SA. Endometriosis. N Engl J Med. 26 2020;382(13):1244-56.

24. Jung H-S, Lee J. The effectiveness of an educational intervention on proper analgesic use for dysmenorrhea. European Journal of Obstetrics \& Gynecology and Reproductive Biology. 2013;170(2):480-6.

\section{Hosted file}

Figure 1.docx available at https://authorea.com/users/344843/articles/471220-prevalence-ofdysmenorrhea-in-adolescents-in-france-results-of-a-large-cross-sectional-study

\section{Hosted file}

Table 1.docx available at https://authorea.com/users/344843/articles/471220-prevalence-ofdysmenorrhea-in-adolescents-in-france-results-of-a-large-cross-sectional-study

\section{Hosted file}

Table 2.docx available at https://authorea.com/users/344843/articles/471220-prevalence-ofdysmenorrhea-in-adolescents-in-france-results-of-a-large-cross-sectional-study

\section{Hosted file}

Table 3.docx available at https://authorea.com/users/344843/articles/471220-prevalence-ofdysmenorrhea-in-adolescents-in-france-results-of-a-large-cross-sectional-study 